\title{
PLANNING FOR SUSTAINABLE DEVELOPMENT OF ENERGY INFRASTRUCTURE: FAST - FAST SIMULATION TOOL
}

\author{
R. BARELKOWSKI \\ West-Pomeranian University of Technology in Szczecin, Poland
}

\begin{abstract}
Energy management has significant impact on planning within local or regional scale. The consequences of the implementation of large-scale renewable energy source involves multifaceted analyses, evaluation of environmental impacts, and the assessment of the scale of limitations or exclusions imposed on potential urbanized structures and arable land. The process of site designation has to acknowledge environmental transformations by inclusion of several key issues, e.g. emissions, hazards for nature and/or inhabitants of urbanized zones, to name the most significant. The parameters of potential development of energy-related infrastructure of facility acquire its local properties - the generic development data require adjustment, which is site specific or area specific. FAST (Fast Simulation Tool) is a simple IT tool aimed at supporting sustainable planning on local or regional level in reference to regional or district scale energy management (among other issues). In its current stage, it is utilized - as a work in progress - in the assessment of wind farm structures located within the area of Poznan agglomeration. This paper discusses the implementation of FAST and its application in two conflicting areas around the agglomeration of Poznan.
\end{abstract}

Keywords: renewable energy planning, spatial planning, sustainability.

\section{PLANNING FOR DECISION MAKING}

Energy management has significant impact on planning within local or regional scale. The consequences of the implementation of large-scale facility or power plant, the erection of a wind farm as well as the strategic decision to exploit geothermal resources, among others, involve multifaceted analyses, evaluation of environmental impacts, and the assessment of the scale of limitations or exclusions imposed on potential urbanized structures and arable land. Rarely, this type of development poses no threat to the environment and rarely it does not result in spatial conflicts while both size (or area) of development as well as intensity of the impact cumulatively alter the existing properties of the environment, most often in an irreversible way.

Planning manifests the necessity to anticipate the course of civilization related and environmental development. Thus, planning becomes an introductory step towards decision making. The decision-making process in reality, contrary to theoretical assumptions indicating the possibility of doing everything by the book, in majority of cases, particularly of small and medium size developments, is based on limited amount of preliminary data, limited research effort, and above all limited amount of time. Time becomes a crucial factor in encouraging those procedures that are efficient in giving the answer sooner even if the risk of making a mistake is increased (one can refer to post-political reality of democracies - decision making is quite often more the result of election cycle impact than argument based). Proposed information technology application displays the necessity to adjust research-based methodologies to those real conditions without hampering the quality of any of steps constituting the planning process. 
When preparatory stages preceding the development of particular local energy production are taken, the stipulated location of infrastructure (or e.g. power plant) must be confronted with the analyses of preliminary environmental transformations. This process includes at least several key issues: emissions and impact area of emissions, dangers and risks for nature with their territorial range, dangers and risks for inhabitants of urbanized zones including areas particularly susceptible for negative impacts, assessment of imposed proprietary transformations and scale of compensations, to name the most significant. Thus, the parameters of potential development of energy-related infrastructure of facility acquire its local properties - the generic development data require adjustment, which is site specific or area specific.

\section{FAST FOR SUSTAINABLE PLANNING}

The concept of utilizing information technology for simulation purposes is well developed throughout the world, but the concept of simple and instant analytic tool is still underestimated. The majority of IT tools are focused on precision of representation and thus attempt to deliver precise simulation tool allowing for sophisticated assessment of spatial management (mostly GIS), for simulation of specialized problems (complex mathematical models, rarely referring to the environment and developed objects as an entity, but still quite self-contained and expert-oriented) or on simple designation of principle functions (quite often extended CAD applications). Only some applications provide either complex abilities including quick preliminary simulation or simplified check-out of general guidelines for selected areas.

The concept behind FAST - fast simulation tool - is to provide a simple tool, which may be applied easily outside of ranks of planners and urban designers. This is intended to become more a platform for discourse between experts (planners and urban designers or specialists of fields to spatial management), authorities which in fact are decision makers, and investors/developers who may be regarded as initiators of various random transformations of the environment. Therefore, FAST is expected to deliver basic approximation of what may be expected as a result of multiple categories of developments located within the area. FAST general concept relied on providing several development-related groups of information: spatial response to development assumptions (area coverage), the main parameters (density, green area, estimated number of users, etc.), infrastructural data (media requirements), and environmental consequences (rate of transformation of land, energy consumption vs. generation, emissions, etc.). The tool, currently still under development, was first tested to examine the potential hazards related to extensive housing and their conflicting border zones by Barelkowski [1]. Soon, however, it appeared necessary to define the properties of various other types of facilities and terrain types potentially conflicting with developmental zones. The catalogue of housing, service and industrial areas has been extended and supplemented with areas dedicated to various types of infrastructure, following the assumption that those pose greatest threat to harmonious, balanced arrangement.

Particularly, peripheral areas encourage the early examination and diagnosis of conflicting conditions. Industrial as well as infrastructural use produces intensive or extensive areas of impact or emissions; therefore, they significantly affect the ability to use adjacent areas for developmental purposes, to maintain biologically active components of the environment, or to be able to profit entirely from cultural potential of the landscape and objects located within. FAST has a modular structure. This allows to add subsequent components and to start with 
selected types of objects not necessarily covering their whole range. When taking into account infrastructural objects related to energy production and energy transfer, the application must acknowledge three main groups of developments: transfer lines with their zones of impact, scattered power production facilities (e.g. wind turbine clusters), and concentrated power production facilities (e.g. biogas power station). At this particular stage, only wind turbine module is operational with three other modules underway. The reason to focus on wind turbines was that this type of development became more and more successful in entering agglomeration peripheral zones and in starting to affect the quality of life of local communities - both in objective and subjective way. Expected tool thus had to implement mechanisms enabling formation of various wind turbine matrixes, both regular and irregular (see [2]). Irregular matrix is usually less efficient but is necessary to follow specific land configuration. The concentration of high obstacles or hills or mountains strongly influences the shape of the calm zone, where wind power cannot be acquired.

\section{WIND TURBINES FOR OR AGAINST URBANIZED AREAS}

Planning for wind turbines must take into account multiple factors, among which the most significant are economic feasibility, efficiency in pursuing principle goals in energy production (which is different from economic feasibility, focusing on narrow aspect of energy output), and environmental and social impacts. Economic feasibility is a result of land availability and related costs, manufacturing and construction costs with the inclusion of benefits gained thanks to subsidies, and energy production costs, which refers to power network connection costs, energy costs, and maintenance costs increased in case of additional compensations. Efficiency refers to climate and location conditions affecting wind parameters, directions and stability of airflow (e.g. usually more stable in offshore locations than in onshore ones), as well as to the size and availability of power network connecting the wind farm to distribution system. Environmental and social impacts determine the absolute no-zone for wind turbines, which often leads to reduction of conditions for assigning the areas of negative location (rejection of locations for wind farms).

The observable tendencies in wind farm planning say much of discrepancy between wind farm design by the book and wind farm design as performed by the developer. This is due to the fact that the above-mentioned factors are not equally validated by the developers who hierarchize them in the following order - starting from economic, making the social and environmental the last. Their interests are backed up by the doctrine and EU goals established within common policy related to the so-called climate change challenge. Therefore, interests weakly represented, while local communities are only indirectly part of administrative processes, contrary to authorities and developers, are astonishingly not supported by the system to achieve balance - they instead support the strong. Opposite, gathering the information on how wind farms perform helps strongly to understand that this kind of solution is not the solution for all cases, for all locations and if only the energetic performance is the key argument behind this type of renewable energy, then clearly locating a wind farm must go beyond mere zones of permanent exclusion and avoid the assumption that allowance may be granted everywhere outside of no-zones.

Wind turbine clusters are perfect examples of fundamental discourse between business and doctrine-driven approach, which focuses on question 'Where wind farm cannot be built?' and social and environmental-driven approach which defines its scope in a different manner 'Where wind farm should be built?' Instead of seeking what mankind will lose in future and how grim will the future become as a result of neglecting the support of renewable energies, 
which may only be as much as sophisticated prognostics with imbued large margin of errors, one should pursue the question what may be gained and lost today, immediately when the decision on wind farm location is made and the process is put into action. For current status and current situation of wind farm at work, we are provided with hard data, we can perform comparative analyses, we may diagnose weaknesses and, finally, we may built credible system of rational establishing the locations for wind turbine clusters to achieve maximum efficiency at minimal losses today.

When discussing planning for location of wind turbine clusters' several groups of factors, but focusing on spatial aspects of the development leads to considering primarily environmental and social issues merged with availability of appropriate land. One may distinguish encouraging or discouraging factors, among others: land function and ownership structure, presence or absence of protected areas in the vicinity (related to the assessment of environmental/cultural impacts), local atmospheric conditions granting efficiency, power network availability, and planned power output. Ultimately, one of the crucial parameters is the power output of single turbine, which defines detailed planning and area to be dedicated to a wind farm. One may start considering the issue of wind farm location from that particular parameter as well as from wind turbine spacing, while these are autonomous features of wind turbine cluster non-related to location properties and they perfectly illustrate the fact that research-based approach is in significant contradiction to practice, based mostly on economic goals of the development. This is perfectly seen not only because researchers focus on hierarchized and alternatively validated set of criteria, but also because limitations research is bound to complexity of considered options. The review of current status of understanding the impacts of wind farms is explained in many sources as too complicated to be efficiently implemented in majority of development cases, e.g. Zhang discusses the issue of objectives underlining that simplistic models evolved, but not to the point to profoundly mirror the real installation. Zhang [3] attempt to include successfully the multiple criteria of evaluation of the optimization of wind farm design. The latest approaches to the problem of wind farm design expand well-known proposals of bi-objective algorithms, like in the case of Kusiak and Li [4] or in the case of Kwong et al. [5].

The representation algorithms evolve and the most recent approaches may be diagnosed as evolutionary algorithms, genetic algorithms, and specific examples of Covariance Matrix Adaptation-based Evolutionary Strategy (CMA-ES), which is explained in elaboration by Wagner et al. [6]. However, as the authors of the latter model point it out, still these models are rough approximations that are unable to depict the mixture of objective and subjective factors influencing the layout of a wind farm (also Wagner et al.). Similarly, the implementation of Particle Swarm Organization (PSO) or Extended Pattern Search (EPS) did not change the environmentally oriented quality of wind farm layout. It is still the result of economic factors with reduction of environmental issues to those purely deterministic (land configuration - elevation, relative height differences, etc.). Even so, results like those provided by Tong et al. display the fragile balance between local constraints of wind farm and expected performance values in terms of economy and power capacity [7].

Turbine spacing is most popular when performed according to array layout, or the so-called 'thumb rule', which depicts the Cartesian offset of subsequent rows and turbines within rows in an abstract, optimal wind farm (Fig. 1). Basic configurations, for simplicity of the model, assume flat surface and skip the problem of terrain roughness and obstacles in the environment, which may obviously influence the locations of particular turbines. The offsets are 


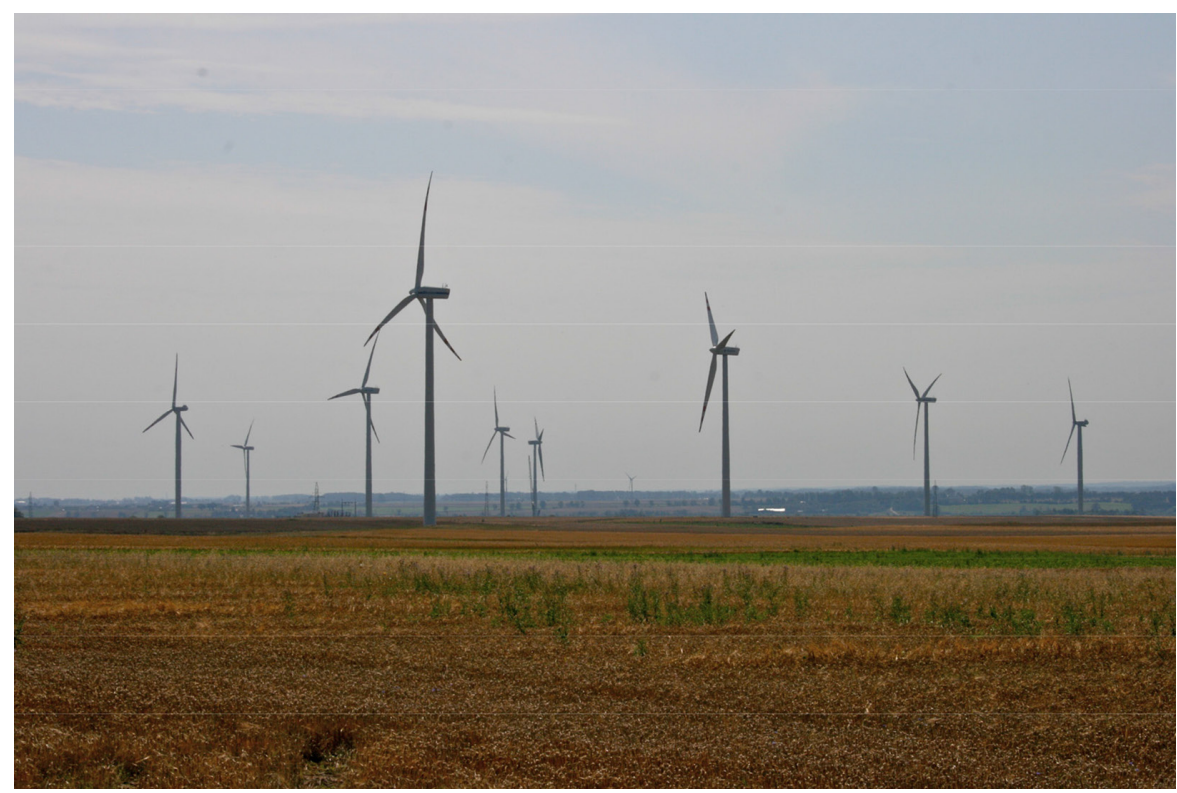

Figure 1: Wind farm near Lisewo, Poland, an example of almost regular matrix spacing. This type of spacing, being purely utilitarian and geometric, ignores unique properties of landscape.

related to rotor movement area, cone of airflow distortion more often referred to as turbine wake, and the area of impact. Those parameters are derivatives from rotor size (rotor size even more than power output). Wind farm spacing was established as relative to rotor size (and power output) since early implementations of wind power.

Currently, the standard of wind turbine scheduled for construction onshore oscillates around and over 2.0 MW, but this value was significantly increased in last decade. When compared with guidelines established in the USA, in State of California in 2006, official recommendations define 0.6 and $1.5 \mathrm{MW}$ standards as reference. In case of $0.6 \mathrm{MW}$, turbines' guidelines indicate spacing resulting in maximum of 10 turbines per $1 \mathrm{~km}^{2}$; however, larger turbines require more spacing, thus they are more dispersed - three turbines per $1 \mathrm{~km}^{2}$ - as per CWEC standards [8]. European guidelines prepared by the Scientific Committee of European Environment Agency [9] for European Commission allow for higher density rate depicted by the value of $10 \mathrm{MW}$ per $1 \mathrm{~km}^{2}$. European Environment Agency performing by the Scientific Committee thus sanctioned the ability to form the matrix in which turbines only moderately decrease the efficiency of subsequent rows.

The review of diverse examples from the world becomes the basis to establish referential matrices in FAST application. Most often matrix offsets are defined by the diameter of a rotor of wind turbine ( $\mathrm{D}$ for diameter). To determine the appropriate reference for the application, it is necessary to go through various proposals. One of them is presented by Ragheb [10], who describes 4D/7D (respectively - distance between turbines in a row/ distance between rows) as one excessively implemented. Its popularity is confirmed with Samorani's analysis, who at the same time points out that the absolute minimum of three 
diameters must be maintained for a matrix to be viable at all. Samorani [11] determines possible sizes of wind farm matrix which span from 3D/5D to 5D/9D. Samorani summarizes in his paper that commercial implementations tend towards more dense clusters, and the distance between turbines in one row are between 3 and 5 diameters, where the distance between rows is never smaller than 5 diameters and limited to 9 diameters not because of power output optimization, but because of economic mechanisms established by the subsidiary system (that is supposed to make wind energy - astonishing assumption - more competitive).

Some spacing templates are proposed in various regions of the world, i.e. in India basic matrix is defined as $4 \mathrm{D} / 8 \mathrm{D}$, with the objection of varied turbine power and turbine size. Document issued in 2011, prepared by the Center for Wind Energy Technology [12], proposes variety of solutions starting from 3D/5D through 3D/10D, 5D/7D, up to 4D/8D. For all those matrices, sources in India provide calculations of losses in power output depending on the density of a matrix. In case of those dense ones, the Center for Wind Energy Technology provides the average losses reach up to $16-17 \%$. These data may, however, present the underestimation of efficiency losses, and differences between simulations and hard data obtained from the observation of clusters at work are still unsatisfactorily large. As analyzed by Loemker and Renkema [13], wake influences the efficiency of up to 50\%, depending on varied conditions, and turbulence intensity of up to $10 \%$. What's more Loemker and Renkema's claim that the number of wakes inflicts only limited power losses was questioned in the research of Sotiropoulos [14]. Sotiropoulos used high-resolution virtual wind simulator (VWiS) combining simulation techniques provided by the IT tools with experimental laboratory work (miniature models of wind farms). Here, the effect of stacking the turbulences and inefficiency in acquiring power from airflows is quite evident.

Polish sources present similar structure of wind farms. An example of this may be found in Banak's analysis of wind farm land coverage indicators. Banak [15] gives an approximation of four $2 \mathrm{MW}$ turbines per $1 \mathrm{~km}^{2}$, suggesting that the maximum of $10 \mathrm{MW}$ per $1 \mathrm{~km}^{2}$ should not be exceeded.

One must notice that the 'thumb rule' is strongly criticized among significant number of researchers. This is a result of applying mathematical methods and representations of empirical models. Among those statements, there is the opinion of Rogers, Slegers and Costello [16], who argue to expand the offsets among rows, simultaneously proving that the distances between turbines in a row are of lesser importance. There is a team of Meyers and Meneveau, who are the advocates of a similar model. They expose the behavior of the wind turbine clusters placed within terrain, namely they prove increasing influence of roughness of terrain on the performance of a wind farm. Getting into conclusion, Meyers and Meneveau [17] argue to increase the offset parallel to prevailing wind direction from 1.5 to 2.0 times. Of course, individual properties of concrete geographical site will determine the alteration of their model, but theoretical models abandoning the impact of land configuration are, in the opinion of those Belgian and American researchers, too deceiving. The majority of researchers support EA, GA, PSO or EPS systems to determine the grid-based approach, which attempts to respond to particular site features and pre-adjusts configuration of wind farm, like Chowdhury et al. [18]. This is also the case, in an interesting implementation of Markov Chain Monte Carlo method (MCMC) with authors - Tzanos et al. [19] - claiming that this kind of approach delivers superior results to typical GA methods.

As always, theoretical models have to be compared with real developments. FAST application was preceded with research on parameters of existing wind farms in Poland and 
abroad, among them Bishop Hill in Illinois (400 MW), Winergy Offshore in Delaware (1100 MW), Twin Groves Wind Farm (396 MW), Shepherds Flat (750 MW), East Otago in Australia (650MW), Horns Rev I in Denmark (160MW) as well as twin farm Horns Rev II (209 MW), Butendiek in Germany (240 MW), East Ayrshire in Scotland (300 MW), Lewis in Scotland (600 MW), Makara Hills in New Zealand (210 MW) - analysis of all those wind turbine clusters indicates maximum saturation of installations at $8.4 \mathrm{MW} / 1 \mathrm{~km}^{2}$ regardless of location. Onshore or offshore locations do not differ with regard to this factor, similarly roughness of terrain also does not contribute significantly to power capacity.

\section{FAST - GENERAL ASSUMPTIONS}

FAST tool is elaborated to work in context of the above-mentioned bulk of research results and achievements, respecting this great contribution. But at the same time, FAST is not intended to replace discussed models - it works to supplement those by providing the opposite assumption of a wind farm being an intruder in the environment. As it was already presented, majority of models build the matrix of a wind farm on the basis of an assumption that economic efficiency must be slightly adjusted to conform to site conditions, and thus provide local optimization of working parameters. To achieve this goal, FAST is to refer to the strategy of sustainable development per analogia to the strategy determined for the edge of the city, by following five key issues: reduction of resources consumption imperative, priority to urban development, maintaining the adaptability of urban nodes, assuring the integrity of urban tissue, both contemporary and future, and maintain proportions among types of spaces (functions), becoming the part of coordinated management and development.

The concept of sustainability imposes responsibility to fulfill the notion of sustainable development, to conform its requirements. FAST, or any other IT tool serving that purpose, should refer to the principle of sustainability due to the fact that renewable energy is supposed to realize human dream of green, emission free energy, an idea that may manifest only partially and only if decision makers will perform their duties with prudence and sensibility as discussed by Barelkowski [20].

FAST works in several steps:

- Wind farm model assimilation or model generation; currently, FAST works only with array type models; however, it can easily import grid-based models from other applications, providing these models are available in exchange format.

- site-specific constraints definition; currently, FAST determines only interactions with predefined objects; however, more broad spectrum of interactions is intended to be included.

- Acknowledgment of windrose and windspeed for emissions and impacts model; it must result in generating variety of diverse factor configurations representing possible efficiency fluctuation.

- Final interaction analysis; generating results.

FAST employs six predetermined schemes of array wind farm clusters in more dense (and simultaneously more common) implementation as well as altered matrix (extended according to the principles formulated by Rogers, Slegers, and Costello) - corresponding to 3D/5D and 4D/8D 1.8 MW and 3.0 MW turbines (Fig. 2). Even without the input of external models, FAST allows to acquire the perspective of the influence the contemporary turbines with most common output have on the environment and social space. 


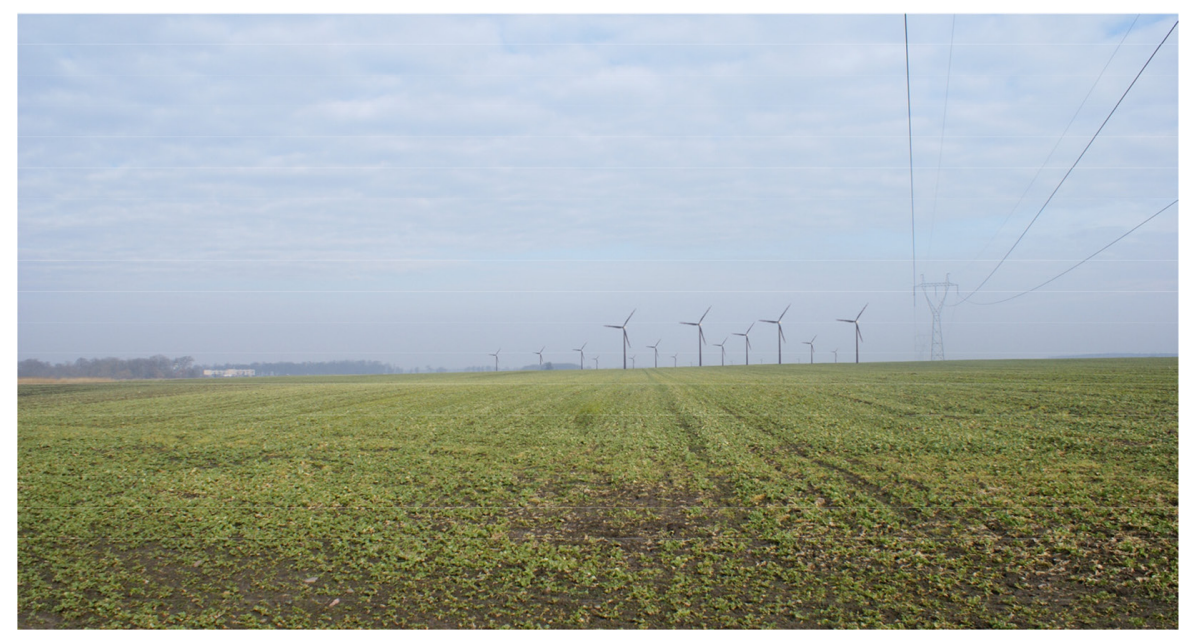

Figure 2: Wind farm simulation in Rostworowo, Rokietnica, performed by research team in parallel with investor's analyses to verify the environmental impacts independently. It is worth mentioning that in Poland and in some other countries, environmental impact assessment is performed by the developer of a farm, resulting in hardly reliable conclusions of EIA.

\section{CASES AS TESTING GROUND}

Two sites of wind farm development became the testing ground for FAST implementation: one located on the border of Rokietnica and Oborniki, and the other on the border of Oborniki and Rogozno. Two controversial locations were primarily assigned by the investors who were using particular conditions for their benefit - first of all, ambiguous regulations in terms of master planning for selected areas as well as for the whole administrative areas (in both cases, the status of renewable energy development was unclear), and secondly, land price was limited due to uncertain status of the area and its predominant agricultural use.

Both cases illustrate the potential missteps in planning procedures as well as in monitoring and environmental impact assessment procedures. Limited conditions proposed for the evaluation of these developments backed by slogans of necessity to follow the agenda of renewable energies, the image of new, multiple jobs created by the construction of wind farm, the idea of significant improvement of local economy due to tax increase related to the implementation of turbines were the arguments used to create positive atmosphere for both developments. None of those were, however, free from generating the conflicting areas, and so complex assessment as well as the opportunity to test FAST emerged (Fig. 3).

In case A, circa 50 turbines were proposed in open agricultural land spanning from Sepno, through Nieczajna to Lulin. The wind farm was supposed to create parallel north-south barrier along Samica river and cut through biologically active areas, including some avifauna-related feeding and nesting grounds (outside of protected zones). Other impacts included areas of potential development of housing (still within $20 \mathrm{~km}$ distance from the central part of the city of Poznan), deformation of landscape in the surrounding of Objezierze complex noteworthy of interest for those appreciating architectural heritage. In case B, wind farm was to become the extension of adjacent farm under construction, run by another operator. Fortunately, much more to the north with regard to the areas of planned development of 


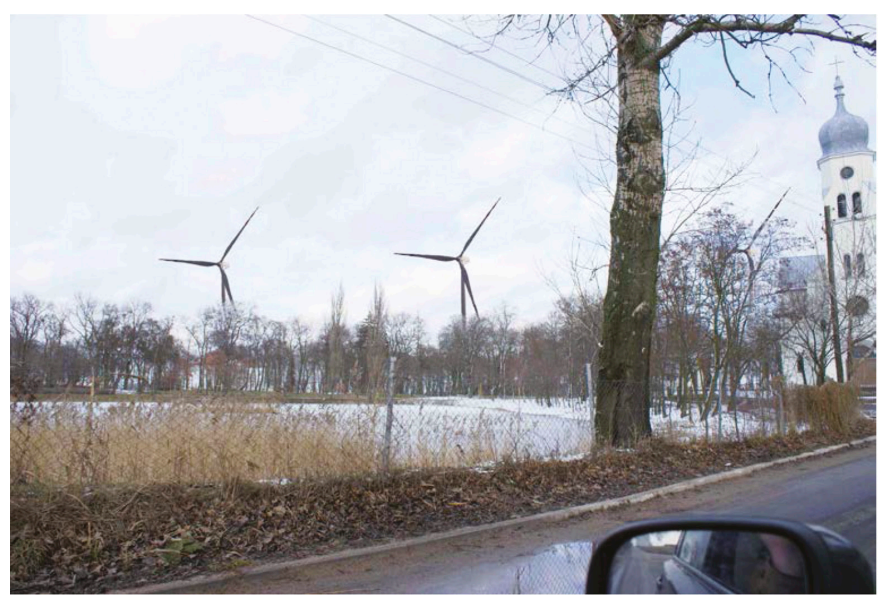

Figure 3: Highly controversial wind farm development at the border of urbanized area of Zydowo, Rokietnica. Simulation made by research team shows the relationship between architectural heritage and planned turbines at a distance of ca. $700 \mathrm{~m}$ from the church.

Table 1: Exemplary excerpt from FAST feedback on sites A and B.

\begin{tabular}{|c|c|c|}
\hline & Case A & Case B \\
\hline Opportunity to produce energy & $\mathrm{E}$ (low) & E (low) \\
\hline Rate of intervention in geologic structure/ soil & 1 & 1 \\
\hline Rate of intervention in hydrologic structure & 0 & 0 \\
\hline Rate of intervention in greening areas, habitats & $4 / 9$ & $3 / 6$ \\
\hline $\begin{array}{l}\text { Rate of intervention in air space (migration of } \\
\text { species, communication) }\end{array}$ & 9 & 7 \\
\hline Rate of intervention in natural landscape & 8 & 8 \\
\hline Rate of intervention in cultural landscape & 9 & 7 \\
\hline Type of spatial intervention & Extensive & Extensive \\
\hline Possible impact on local environment & Only negative & Only negative \\
\hline Total estimated impact on environment & 9 & 7 \\
\hline $\begin{array}{l}\text { Possibility to use renewable energy within an } \\
\text { administrative area for individual use }>\text { actual }\end{array}$ & Yes $>$ No & Yes $>$ No \\
\hline $\begin{array}{l}\text { Possibility to use renewable energy within an } \\
\text { administrative area for industrial use }>\text { actual }\end{array}$ & No $>$ No & No $>$ No \\
\hline
\end{tabular}

Poznan agglomeration, which would result in immediate conflict with urban structures, the second example became provocative due to its potential relationship with already established infrastructure and competitive wind turbines. While on existing site, larger than planned in Oborniki, there were already 8 turbines under construction or with administrative approval, the scheme of 13 new turbines of $2.3 \mathrm{MW}$ capacity each, and potential mutual interaction within wake of each other's turbines has become (and still is) a matter of fierce debate. 
In case A, investor has decided to keep the scheme of the wind farm disclosed; therefore, FAST generated 4D/8D matrix for the simulation purposes. In case $\mathrm{B}$, scheme was provided by the investor, and dense packing of turbines forced research team to analyze not only the disposition delivered but also another one assuming 3D/5D structure. In both cases, the results for wind farms were confronted with environmental-related algorithms defining zones of exclusion and zones of impact to establish the optimization. FAST generated the assessment of predetermined factors according to ECA (and CSSM) methodology (see Table 1).

\section{FAST BEGINNING}

This paper should be considered as a presentation of work in progress. It shows, as a subsequent work related to research conducted in the area of Poznan, as documentary of realization that research reality to be efficient when confronted with time factor must be extended on the field of information technology. Thus, FAST provided - as for now - efficient and viable option to support decision-making process. Simultaneously, however, it revealed several weaknesses.

First of all, implementation models for wind farms are non-editable and therefore do not enable to check the correctness of delivered material. Whether FAST should be extended to become an independent simulation tool for wind farm spacing is another issue. Second, FAST should implement more interactions and display more relationships between wind farms (in that particular case) and housing or other urban developmental areas. Third, and quite obvious for research team is the evident needed for more options included in elaborated application more acknowledged aspects of land configuration, landscape delimitations, exposition fields, among many others, which could make FAST more profoundly working tool.

Still, the tool works well with the basic support of decision-making process, giving programmed feedback as a response for fundamental criteria given within CSSM methodology. Estimated time of generating the results if wind farm model is delivered does not exceed two working days (12 hours). Being fully aware of the work ahead, FAST appears to be a promising extension and assistance for planners.

\section{REFERENCES}

[1] Barelkowski, R.,The edge of the [dis]order. (eds.) The Sustainable City VII. Urban Regeneration and Sustainability, eds M. Pacetti, G. Passerini, C.A. Brebbia \& G. Latini, Wessex Institute of Technology, WIT Press, Southampton \& Boston, pp. 764-765, 2012. doi: http://dx.doi.org/10.2495/sc120642

[2] C.f. Mehlg, Planning Guidelines, The Department of the Environment, Heritage and Local Government, The Minister of the Environment, Heritage and Local Government (as published in Section 28 of the Planning and Development Act, 2000), Dublin, pp. 37-44, 2007.

[3] Zhang, P.Y., Topics in wind farm layout optimization: analytical wake models, noise propagation, and energy production, University of Toronto, Canada, pp. 4-5, 2013.

[4] Kusiak, A. \& Li, W., , Estimation of wind speed: a data-driven approach. Journal of Wind Engineering and Industrial Aerodynamics, 98(10), pp. 562-564, 2010. doi: http://dx.doi.org/10.1016/j.jweia.2010.04.010

[5] Kwong, W.Y., Zhang, P.Y., Romero, D., Moran, J., Morgenroth, M. \& Amon, C., Multiobjective optimization of wind farm layouts under energy generation and noise propagation. Proceedings of the ASME 2012 International Design Engineering Technical 
Conferences \& Computers and Information in Engineering Conference IDETC/CIE 2012, Chicago, pp. 5-6, 2012.

[6] Wagner, M., Neumann, F., Veeramachaneni, K. \& O'Reilly, U.-M., Optimizing the layout of 1000 wind turbines. European Wind Energy Association Annual Event, Brussels, Belgium, pp. 5-6, 2011, available at: https://cs.adelaide.edu.au/ markus/pub/2011ewea. pdf (accessed 22 March 2014).

[7] Tong, W., Chowdhury, S., Mehmani, A. \& Messac, A., Multi-objective wind farm design: exploring the trade-off between capacity factor and land use. 10th World Congress on Structural and Multidisciplinary Optimization, Orlando, FL, pp. 5-6, 2013.

[8] CWEC, Permitting setback requirements for wind turbines in California. PIER Interim Project Report, California Wind Energy Collaborative for California Energy Commission, November 2006, CEC-500-2005-184, Davis, pp. 4-6, 2006.

[9] European Environment Agency, Europe's onshore and offshore wind energy potential. An assessment of environmental and economic constraints, EEA Technical Report, Copenhagen, vol. 10, p. 51, 2009.

[10] Ragheb, M., Orography and Wind Turbine Siting, 7, 2013.

[11] Samorani, M., The Wind Farm Layout Optimization Problem, pp. 11-12, 2011.

[12] CWET, A Technical Note on Micro-siting of Wind Turbines, Centre for Wind Energy Technology, Ministry of New \& Renewable Energy, New Delhi, 15, 2011.

[13] Loemker, C. \& Renkema, D., Wake model validation, GE Wind Energy, TU Delft, Billind/Hovsore, 2006, available at: http://www.ieawind.org/task_23/Subtask_1S_ docs/Task23_Billund/15\%20Wake\%20mod\%20vali\%20DR.pdf (accessed 22 March 2014).

[14] Sotiropoulos, F., Development of a high-resolution virtual wind simulator for optimal design of wind energy projects, Saint Anthony Falls Laboratory, Minneapolis, MN, pp. 18-19, 2013.

[15] Banak, M.J., Lokalizacja elektrowni wiatrowych - uwarunkowania srodowiskowe i prawne, Czlowiek i Srodowisko, 34(3-4), p. 120, 2010.

[16] Rogers, J., Slegers, N. \& Costello, M., A method for defining wind turbine setback standards, Wind Energy, 15(2), pp. 289-303, 2011. doi: http://dx.doi.org/10.1002/we.468

[17] Meyers, J. \& Meneveau, C., Optimal turbine spacing in fully developed wind-farm boundary levels, Wind Energy, 15, pp. 314-315, 2011. doi: http://dx.doi.org/10.1002/ we. 469

[18] C.f. Chowdhury, S., Zhang, J., Messac, A. \& Castillo, L., Characterizing the influence of land configuration on the optimal wind farm performance, Multidisciplinary Design and Optimization Laboratory, ASME 2011 International Design Engineering Technical Conferences, and Computer and Information in Engineering Conference, Washington, DC, p. 3, 2011. doi: http://dx.doi.org/10.1115/detc2011-48731

[19] Tzanos, J., Margellos, K. \& Lygeros, J., Optimal wind turbine placement via randomized optimization techniques, ETH Zurich, pp. 8, Summarization of Research being the part of MoVeS project, FP7-ICT-257005, supported by the European Commission, pp. 5-7, 2011.

[20] Barelkowski, R., Sustainability - myth, reality, and future. Planning and renewable energy management, The Sustainable City VIII. Urban Regeneration and Sustainability, eds S.S. Zubir \& C.A. Brebbia, Wessex Institute of Technology, WIT Press, Southampton \& Boston, pp. 792-793, 2013. doi: http://dx.doi.org/10.2495/sc130662 